\title{
Positivism versus Interpretivism: Fire-war on the Methodological Approach in the Study of Organisational Culture
}

\author{
Oluwafemi Emmanuel Idowu \\ Faculty of Health, Social Care and Education \\ $2^{\text {nd }}$ Floor William Harvey Building, Anglia Ruskin University \\ Bishop Hall Lane, Chelmsford, CM1 1SQ UK \\ Email: emmanuel.idowu@anglia.ac.uk
}

Received: November 11, 2016 Accepted: December 09, 2016 Published: December 31, 2016

doi:10.5296/ijhrs.v6i4.10403 URL: http://dx.doi.org/10.5296/ijhrs.v6i4.10403

\begin{abstract}
Scholars interested in organisational culture research have kept a fire-war going for years discussing the pros and cons of quantitative versus qualitative ways of examining the concept. The qualitative camp points out that the richness of perceptions and experiences inside an organisation are vital to the deep understanding of cultural dynamics, and they sniff that organisational culture cannot be constrained to a two by two matrix or a list of dimensions. On the other camp, quantitative scholars argue that leaders need to have some hard data, and that the drawbacks of getting slow, expensive, possibly unreliable (unique to the interpretation of the researcher) qualitative information make the usefulness iffy at best. The limitations of the existing studies on organisational culture, serve as the main crux of this article. The author is of the view that existing studies on the concept of organisational culture, may have failed to present a comprehensive picture of the dynamics of culture in the organisation. This article, therefore, argues for the use of mixed methodologies in the study and analysis of organisational culture.
\end{abstract}

Keywords: Organisational Culture; Mixed methodologies. 


\section{Introduction}

The understanding of the dynamics of culture in the organisation has been of intense academic interest to scholars (Idowu, 2017) because the dynamics of organisational culture (OC) has a significant impact on the long-term performance of any organisation (Ogbonna \& Harris, 2008). Ogbonna and Harris (2008:4) stressed further that "some of the studies that examined the concept of organisational culture have attracted criticisms on the grounds of methodological weaknesses." One of the gaps identified in most of the existing studies (Idowu, 2017) on organisational culture is the adoption of a functionalist approach and the use of quantitative methodologies. The consequence of such an approach has been that the multi-dimensionality of the complex constructs and dynamics of OC have not been captured in such studies (Idowu, 2017). Given the conceptualisation of OC as multifaceted (see for example, Schein, 2011), it can be argued that those studies have methodological weaknesses in the way OC is investigated and analysed (Ogbonna \& Harris, 2008). This article, therefore, advocate for the need to adopt mixed methodologies when exploring and analysing the concept and dynamics of organisational culture.

One of the controversies by scholars, surrounding investigating and analysing OC centres on the degree of accuracy that can be achieved through research methodologies and methods. Scholars are divided along organisational behaviourist/anthropological lines in debating whether subjective interpretation of a culture yields accuracy beneficial to the researcher. A quantitative versus qualitative debate rages amongst OC scholars with respect to methodologies best used to assess OC (Mannion et al., 2009). The review of the argument for and against quantification reveals that they arise from what Ogbonna and Harris (2008) described as a subjective versus objective debate, as reflected in positivism and interpretivism. The basic preposition comes from the premise that social phenomena are not amenable to the techniques of quantitative analysis in the same way as natural sciences. This finds full support in the observation of Parker (2014) that the struggles between objective and subjective choices are due to the ontological and epistemological differences underlying qualitative and quantitative methods, as well as choices arising from the fundamental ideas about the nature of organisations.

However, many eminent scholars believe that quantitative techniques could be used for investigating and analysing OC (Idowu, 2017). They believe that there are aspects which are amenable to quantitative analysis. Furthermore, Parker (2014) poignantly remark that if qualitative methods alone had been used in the study of social phenomenon, the study of OC may not have reached the heights it has reached today. However, it is also true that there are aspects of OC such as basic assumptions (see for example, Schien, 2011) which may not be amenable to quantitative analysis.

Schein (2011) argues that depth of understanding may not be possible through quantitative methodologies and they are not able to penetrate what is superficial in order to decipher the values, beliefs and assumptions held by employee. A more pertinent example could be what Schein (2011:32) called "theories in us". 'Theories in us' are the actual reasons for behaviour, which people rarely acknowledge and a questionnaire may not be able to capture this. Clearly, 
there are aspects for which qualitative analysis is suitable just as there are aspects where quantitative approach is also appropriate and they should therefore be used to capture those aspects for which they are best suited.

\section{Methodological Shortcomings of Existing Studies on Organisational Culture}

There are broadly two traditions of academic enquiry, quantitative and qualitative methods (Bryman, 2004). Quantitative research uses statistical models to explain data, deals with numbers and is considered hard research. By contrast, qualitative research deals with interpreting social realities, avoids numbers and is considered soft research. Bryman (2004:100) stressed that because quantitative research is deductive, researchers deal directly with operationalisation, prediction, and testing. Quantitative research therefore places great emphasis on procedure and statistical measures of validity. On the other hand, the most fundamental characteristics of qualitative research is its express commitment to viewing, for example, events, actions, norms, and values from the perspective of the people being studied. This approach clearly involves a preparedness to empathise with those being studied, but it also entails a capacity to penetrate the frames of meaning with which they operate.

Furthermore, the quantitative tradition adopts an objective approach, stresses more on breath rather than depth and is aimed at generalisation (Denzin \& Lincoln, 2000; Easterby-Smith et al., 2011). A quantitative methodology to cultural exploration may be preferred in circumstances in which more intensive methods might be ruled out because of time constraints, intrusiveness, human resources, or organisational policy (Brown, 1998; Scot et al, 2006). As such, a quantitative methodology is assumed to maximise precision, systematization, repeatability, comparability, convenience, large scale, unobtrusiveness and cost-effectiveness (Coolican, 2003). Of course, these assumptions may be far from secure, especially when scrutinised from a qualitative research paradigm. Even from a quantitative paradigm, the degree of statistical precision of some research can be questionable (Coolican, 2003).

By contrast, qualitative methodology deals with how people understand their experiences. The use of this methodology in the study of OC is often associated with a broader theoretical critique of quantitative methodology. This critique tends to point to certain problems with naturalism. Naturalism is the application of the methods of the natural sciences to the study of social or psychological phenomena (Creswell, 2009). Thus, qualitative methodology in the study of OC aims to explore meaning, and might well be chosen because it can be used for the investigation of issues which, for ethical, practical or epistemological reasons, are difficult to 'measure.'

The qualitative methodology lay stress on depth rather than breath and is not aimed at generalisation (Creswell, 2009). Denzin and Lincoln (2000) argued that the qualitative tradition is both process and explorative-oriented, focuses on understandings, is holistic in its approach, and follows a rational and interpretive approach. Qualitative studies are often found to be descriptive in contrasts to the rigorous approach which is often associated with quantitative studies. It can be seen that the roots of this arguments can be traced back to the objective versus subjective debate (Gummerson, 2011) represented by positivism and 
interpretivism.

The struggles between subjective and objective choices are due to the ontological and epistemological differences and have a basis in the fundamental ideas about the nature of organisations (Brown, 1998; Schien, 2011; Alvesson, 2005). The assumed advantage of a qualitative paradigm to exploring OC research is the ability to identify structures through the patterns displayed by individual behaviour (Schein, 2011; Alvesson, 2005). Such approaches allow for the detailed and meaningful analysis and examination of underlying values, beliefs, and assumptions in the culture of an organisation. As a result, a rich account of the cultural dynamics and complexity within an organisation can be identified (Alvesson, 2005). As such, a qualitative approach scores highly on heurism, flexibility, adaptiveness, depth, and realism (Denzin \& Lincoln, 2000; Rubin \& Rubin, 2005).

While these two methodologies to research are often presented as if they were in binary opposition to one another, they can also be used to complement one another.

Therefore, the interpretivist and positivist approach to understanding OC has some appeal. The positivist and interpretivist both believe that to understand the world of meaning, one must interpret it. Schein (2011) argued that OC encompasses the values, beliefs, and assumptions of people and these are located at the level of the unconscious so much so that they are powerful enough to drive behaviour frequently without people being aware of them. Many of such values, beliefs and assumptions are taken-for-granted and the power of a survey instrument to capture this is at best, extremely suspect, if not impossible. This emotional and subjective worldview is best captured through qualitative analysis (Schein, 2011). It may be because of this, that Ogbonna and Harris (2008) warns that methods other than mixed methodology for the study and analysis of OC would become problematic.

\section{Methodological Stance Appropriate to Studying Organisational Culture}

If qualitative and quantitative methodology offer different strengths and weakness, choosing between the two paradigms hinge on a trade-off between depth and breadth of data. Qualitative methodology offer detailed insights, while qualitative methodology allow for the examination of larger sample sizes. One way to harness the strengths of both paradigms is to combine them. A very interesting point that is often overlooked is that both qualitative and quantitative traditions contribute to each other. The crucial aspect of this interdependency is that, devoid of the descriptiveness associated with qualitative research tradition, research in the quantitative stream is rendered extremely difficult, if not impossible. Bowling (2002) puts it very bluntly when she points out that without the "creative leap" made by qualitative research, the quantitative researchers would be left with no theory to test. Bowling (2002:87) goes on to add that "we uncover all kinds of relationship in our hard data, but it is only through the use of this soft data that we are able to explain them."

According to Bowling (2002) there are three purposes for mixed-methods design; triangulation (that is to corroborate data and obtain convergent validity), complementarily (to fully understand and explain the results of analyses), and development (to guide further data collection, sampling or analysis). Triangulation in organisational cultural assessment may 
help to reduce bias and increase validity, while complementarity will lead to deeper understanding of the OC, enabling analysis of the values and assumptions driving behaviours within the organisation.

The term triangulation was used by Bowling (2002) to mean not only examining the same phenomenon from multiple perspectives but also increasing understanding when new or deeper insight emerges. Creswell (2009) maintains that triangulation is the use of multiple perceptions or observations to provide verification or clarify meaning. He explains that " $n o$ observations or interpretations are perfectly repeatable" (p. 44), thus, analysing the phenomenon from different perspectives automatically serves to clarify meaning. A more common and narrow definition of triangulation by Denzin and Lincoln (2000:29) is that "it is a vehicle for cross-validation when multiple methods produce comparable data". By mixing methods a greater cultural understanding with respect to scope and depth will be achieved through paradigm complementarity.

The most significant and crucial issue, however, is that OC, like many social phenomena, is not easily amenable to quantitative rigours. It is argued in the literature that OC encompasses the values, beliefs, and assumptions of people and these are located at the level of the unconscious so much so that they are powerful enough to drive behaviour frequently without people being aware of them (Idowu, 2017; Schein, 2011). Many of such values, beliefs and assumptions are taken-for-granted and the power of a survey instrument to capture this is at best, extremely suspect, if not impossible (Jung et al., 2009).

Bryman (2004) argues that the two methodologies are probably a lot more complimentary than researchers give them credit for. There is therefore a growing interest among scholars that are interested in the study of OC, in what each methodology can offer to the other, while still respecting the differences (Idowu, 2017; Scott et al., 2006) and the need for adopting mixed methodologies and methods in the study and analysis of OC (Ogbonna \& Harris, 2008).

\section{Mixed-Methods the Preferable Choice in the Study of Organisational Culture}

Each method has its strengths and weakness, and is particularly suitable for a particular context. However, there are occasions when qualitative researchers draw on quantitative methods and vice versa, therefore they could be used interchangeably. Due to words constraint, this article will discuss and review two of the most methods used in the study and analysis of organisational culture.

\subsection{Questionnaire}

Questionnaire is a way of collecting information about a range of phenomena. It usually involves asking respondents questions. It is, "the systematic gathering of information from a sample of people, events, literature records and so forth" (Bowling, 2002:61). According to Bowling (2002:174) the process of data collection is through "...a sample of population of interest, usually by personal interviews (face-to- face or telephone, postal or other self-completion questionnaire methods or diaries." Questionnaires are also considered to be an efficient mechanism for gathering data when the researcher knows specifically what is 
required and how to measure the variables of interest and importance (Robson, 2002).

Bryman (2004) and Creswell (2009) offer some of the advantages and disadvantages of questionnaires in research. There are many advantages to be derived from using the questionnaire. The first advantage is the cost. It is cheaper than personal interviewing, and it does not require a trained interviewer. All it need is the cost of planning, sampling, duplicating, mailing, and providing stamped, self-addressed envelopes for the return. The processing and analysis are usually also simpler and cheaper than those of the interview. Another advantage of questionnaire is the reduction in biasing error. Questionnaire reduces the biasing errors that might result from the personal characteristics of the interviewers and from variability in their skills. Questionnaire also makes it possible to ensure confidentiality by maintaining the anonymity of the respondents. The assurance of anonymity with questionnaires is especially helpful when the survey deals with extensive issues.

However, in spite of its advantages, there are some disadvantages in using this technique of data collection. First, due to its informal nature, questionnaire requires simple questions to be asked. The questionnaire can be used as an instrument for data collection only when the questions are straightforward. Another disadvantage is that there is no opportunity to probe further. The answers have to be accepted as final, there is no opportunity to probe the given answer. Questionnaire does not also allow the interviewer control over who fills in the questionnaire. Researchers have no control over the respondent's environment, thus they cannot be sure that the right person completes the questionnaire. There is also sometimes, low response rate to questionnaires. The final disadvantage of the questionnaires (probably the most serious problem) is that they often fail to obtain an adequate response rate.

OC questionnaire method have been criticised for the fact that it is not possible for them to map out a culture's underlying assumptions, because they are unconscious and often only poorly explainable and strongly influenced by the researcher's own conceptions. The results are skewed by matters that the researcher has considered important. Often the questionnaire reveals self-evident facts or matters that are only interesting from a research standpoint. The researcher cannot know, with the questionnaire, in advance which dimensions are significant in the organisation under study, from the point of view of organisational dynamics. The biggest problem in using questionnaire is therefore the basis on which the dimensions to be measured should be chosen. It is difficult to know in advance what one should ask (Schein, 2011).

Bryman (2004) mentioned another problem of questionnaires, namely that they measure views but not actions. Schein (2011:67) further criticises questionnaires because "culture is unconscious and self-evident to those who work within it, it cannot be studied with compulsive methods, such as questionnaire forms and to reach the underlying assumptions, one has to observe and interview." OC questionnaire methods have been criticised for the fact that it is not possible for them to map out a culture's underlying assumptions, because they are unconscious and often only poorly explainable (Schein, 2011). However, if used correctly, questionnaires can provide sufficiently valid descriptive information about an organisation and particularly about the views and attitudes of its staff. OC questionnaires can also be used 
to clarify the various connections between $\mathrm{OC}$ variables and to explain statistically the differences found.

\subsection{Interview}

Understanding the significance of the dynamics of OC requires research that is more than questionnaire methods, such as interviews, observation and the analysis of documents. Only then can one answer the cultural why and how questions. For instance, Robson (2002:272) stated that "face to face interviews offer the possibility of modifying one's line of enquiry, following up interesting responses and investigating underlying motives in a way that postal and other self-administered questionnaire cannot."

Bowling (2002), Robson (2003) and Bryman (2004) offer some of the advantages and disadvantages of interviews in research. The first advantage of interviews is its flexibility. Interviews allow for greater flexibility in the questioning process. The interview allows the interviewer to determine the wording of the questions, to clarify terms that are not clear, to control the order in which the questions are presented, and to probe for additional and more detailed information. Interviews also make it possible to control interview situation. This is a major advantage because it allows greater control over the interviewing situation. An interviewer can ensure that the interviewee answer the questions in the appropriate sequence. Another advantage of the interview is the high response rate. The personal interview results in a higher response rate than mail questionnaire. Respondents who normally would not respond to a mail questionnaire can be more easily reached and interviewed. Finally, in interviews, collection of supplementary information is possible. An interviewer can collect supplementary information about the respondent. This may include background information about the respondents' personal characteristics and their environment that aid the researcher in the interpretation of the results.

With interviews it is possible to bring out subjective opinions and views on the significance of issues, which is not always possible with a structured form. Moreover, the uncovering of entirely new, surprising issues and ideas is more probable in interviews than in questionnaire studies. Interviews permit very different sorts of information to be collected. In interviews one can enquire about the justifications for actions and different measures. These justifications reveal the kind of meanings that individuals assign to their actions (Bryman, 2004).

In spite of its advantages there are some obvious disadvantages of the interview technique. The first disadvantage is the high cost. The cost of interview studies is significantly higher than that of mail survey. There are costs involved in the organisation required for selecting, training, and supervising interviewers, in paying them, and in the travel time required to conduct interviews. Another disadvantage is interviewer bias. The interview allows for greater flexibility, which is its chief advantage, however, sometimes this leaves room for personal influence and bias of the interviewer. In interview, there is also lack of respondent's anonymity. The interview lacks anonymity, which the questionnaire typically provides. Often the interviewer knows all or many potential respondents (or at least their names, job titles, and telephone number). Thus, the respondent may feel threatened or intimidated by the 
interviewer, especially when the topic or some of the questions are of a sensitive nature.

There are also certain problems common to interview studies. Speaking about issues or imaginary behaviour is not the same thing as acting in a natural situation. Imaginary situations lack the emotional charge of real situations. The interview situation also influences answers. The interviewer in the situation is at least an imaginary authority, and thus the interviewees may feel they are in some sort of test that is enquiring about the correct procedure - not necessarily that which is implemented in practice. The main problem as far as interviews are concerned is the choice of themes and questions. Bryman (2004) states that structured interviews partly suffer from the same problems and the same distortions as questionnaires.

Interviews could also result in the interviewee telling stories which may not be relevant and which could make compilation, comparison and analysis of data extremely difficult. This could be further complicated by the lack of appreciation on the part of the researcher to the nuances of the context, which makes it difficult for the researcher to distinguish between such disjointed expressions. Another issue is that interviews could be used as an opportunity by people to air their frustrations and grievances (Easterby-Smith et al., 2011).

\section{Conclusion}

The rationale for adopting mixed methodological approach in the study of OC has been discussed. The author affirms that the strength of the quantitative methods lies in their potential to overcome the limitations of the qualitative approaches. The study results, using mixed methodologies and methods, will be more robust, in that, greater validity will be accomplished through data triangulation, and greater cultural understanding will be attained. Finally, by mixing methodologies and methods at the data and paradigm level, scholars will achieve a more complete understanding of the complexities of OC in relation to its dynamics and multi-dimensionality of the complex constructs of culture in the organisation.

\section{Reference}

Alvesson, M. (2005). Understanding Organisational Culture, (3 ${ }^{\text {rd }}$ edition). London: Sage Publication.

Bartunek, J. M and Seo, M. (2002). Qualitative research can add new meanings to quantitative research. Journal of Organisational Behaviour 23(2): 237-242.

Bell, J. (1999). Doing your Research Project: A Guide for First Time Researchers in Education and Social Sciences. Buckingham: Open University Press.

Bowling, A. (2002). Research Methods in Health: Investigating Health and Health Services. Buckingham: Open University Press.

Bryman, A. (2004). Social Research Methods ( ${ }^{\text {nd }}$ Edition) Oxford: Oxford University Press. 


\section{Macrothink}

International Journal of Human Resource Studies

ISSN 2162-3058 2016, Vol. 6, No. 4

Coolican, H. (2003). Research Methods and Statistic in Psychology, (2 ${ }^{\text {nd }}$ Ed.). London: Hodder and Stoughton.

Creswell, J.W. (2009). Research Design: Qualitative, Quantitative and Mixed Methods Approaches. Thousand Oaks, CA: Sage Publications.

Denzin, N.K. and Lincoln, Y.S. (2000). Introduction: the discipline and practice of qualitative research. In Denzin, N.K. and Lincoln, Y.S. (Eds). Handbook of Qualitative Research. California: Sage, pg. 1-28.

Easterby-Smith, M., Thorpe, R., and Lowe, A. (2011). Management Research: An Introduction. London: Sage.

Gummersson, E. (2011). Qualitative Methods in Management Research. CA: Sage.

Idowu, O.E. (2017). Understanding Organisational Culture and Organisational Performance: Are They Two sides of the Same Coin? Journal of Management Research, Vol. 9, No. 1 pg. $12-21$.

Jung, T., Scott, T., Davies, H.T.O., Bower, P., Whalley, D., McNally, R. and Mannion, R., (2009). Instruments for Exploring Organisational Culture: A Review of the Literature. Public Administration Review, pg. 1087 - 1096.

Mannion, R., Davies, T.O. and Martin N. M. (2009). Cultures for Performance in Healthcare. Maidenhead, UK: Open University Press.

Ogbonna, E and Harris, L.C. (2008). Leadership style, organizational culture and performance: Empirical evidence from UK Companies. International Journal of Human Resource Management 11: 766-788.

Parker, M. (2014). Organisational Culture and Identity: Unity and Division of Work. London: Sage.

Robson, C. (2003). Real World Research. Oxford: Blackwell.

Rubin, H. J. and Rubin, I. S. (2005). Qualitative Interviewing: The Art of Hearing Data, $2^{\text {nd }}$ ed. London: Sage.

Schein, E.H. (2011). Organisational Culture and Leadership ( $3^{\text {rd }}$ Ed.). California Jossey-Bass.

Scott, J.T., Mannion, R., Davies, H.T.O. and Marshall, M.N. (2006). The quantitative measurement of organisational culture in healthcare: What instruments are available? Health Services Research 9(5): 76-83. 


\section{Macrothink}

International Journal of Human Resource Studies

ISSN 2162-3058

\section{Copyright Disclaimer}

Copyright for this article is retained by the author(s), with first publication rights granted to the journal.

This is an open-access article distributed under the terms and conditions of the Creative Commons Attribution license (http://creativecommons.org/licenses/by/3.0/). 